\title{
Aortic no-touch technique makes the difference in off-pump coronary artery bypass grafting
}

\author{
Maximilian Y. Emmert, MD, ${ }^{\text {a } B u r k h a r d t ~ S e i f e r t, ~ P h D, ~}{ }^{\mathrm{b}}$ Markus Wilhelm, MD, ${ }^{\mathrm{a}}$ Jürg Grünenfelder, $\mathrm{MD},{ }^{\mathrm{a}}$ \\ Volkmar Falk, MD, ${ }^{\mathrm{a}}$ and Sacha P. Salzberg, $\mathrm{MD}^{\mathrm{a}}$
}

Objectives: Both off-pump surgery (OPCAB) and aortic no-touch technique reduce stroke after coronary artery bypass grafting (CABG). We evaluate the impact of partial aortic clamping (PC) versus a no-touch technique using either the HEARTSTRING system (HS) or total arterial revascularization (TAR) on the incidence of stroke.

Methods: From 2004 to 2009, 4314 patients underwent myocardial revascularization. Patients either underwent OPCAB $(n=2203)$ or conventional on-pump CABG $(n=2111)$. The OPCAB cohort was divided into 2 subgroups: patients requiring proximal anastomosis applying PC $(\mathrm{n}=567)$ or a "no-touch" technique with the HS $(n=1365)$. Patients who received TAR $(n=271)$ served as a control group (gold-standard). Data collection was performed prospectively using a propensity score (PS)-adjusted regression analysis. End points were stroke, mortality, major adverse cardiac and cerebrovascular events (MACCE), and a noncardiac composite end point including respiratory failure, renal failure, and bleeding.

Results: The mortality rate $(1.6 \%$ vs $2.4 \%$; propensity-adjusted odds ratio $[\mathrm{PAOR}]=0.51 ; \mathrm{CI} 95 \%, 0.26-0.99$; $P=.047)$, MACCE $(7.9 \%$ vs $17.1 \%$; PAOR $=0.67$; CI 95\%, 0.52-0.84; $P=.001)$ including myocardial infarction $(1.1 \%$ vs $2.2 \%$; PAOR $=0.50$; CI $95 \%, 0.26-0.98 ; P=.044)$ and stroke $(1.1 \%$ vs $2.4 \%$; PAOR $=0.35$; CI $95 \%, 0.17-0.72 ; P=.005$ ) as well as the noncardiac composite (PAOR $=0.46 ; \mathrm{CI} 95 \%, 0.35-0.91 ; P<.001$ ) were significantly lower for OPCAB when compared with on-pump CABG. In comparison with PC, OPCAB patients undergoing the HS approach had significantly lower frequencies of stroke $(0.7 \%$ vs $2.3 \%$; PAOR $=0.39$; CI $95 \%, 0.16-0.90 ; P=.04)$ and MACCE $(6.7 \%$ vs $10.8 \%$; PAOR $=0.55$; CI $95 \%, 0.38$ $0.79 ; P=.001)$, and these results were similar to those of the control group, who underwent no-touch TAR (stroke rate, $0.8 \%$; MACCE, $7.9 \%$ ).

Conclusions: Our results confirm that OPCAB is superior with regard to risk-adjusted outcomes. There is no difference in the stroke rate when comparing on-pump CABG versus applying partial aortic crossclamping in OPCAB. Whenever a proximal anastomosis is needed, a no-touch technique should be applied, that is, using the HS device. (J Thorac Cardiovasc Surg 2011;142:1499-506)

Earn CME credits at

http://cme.ctsnetjournals.org

Stroke is one of the most feared complications after surgical coronary revascularization and is associated with high mortality, morbidity, and costs. ${ }^{1,2}$ Previous studies have reported an incidence ranging from $1 \%$ to $5 \%{ }^{3-5}$ depending on the type of operation, preoperative comorbidities, and the general health condition. ${ }^{6}$ Most of the known risk factors, such as peripheral vascular disease, left main disease, or di-

\footnotetext{
From the Clinic for Cardiovascular Surgery ${ }^{\mathrm{a}}$ and the Biostatistics Unit, ${ }^{\mathrm{b}}$ Institute of Social and Preventive Medicine, University of Zurich, Zurich, Switzerland. Disclosures: Authors have nothing to disclose with regard to commercial support. Received for publication Jan 19, 2011; revisions received March 19, 2011; accepted for publication April 26, 2011; available ahead of print June 17, 2011.

Address for reprints: Maximilian Y. Emmert, MD, Department of Cardiovascular Surgery, University Hospital Zurich, Raemi Street 100, 8091 Zurich, Switzerland (E-mail: maximilian.emmert@usz.ch).

$0022-5223 / \$ 36.00$

Copyright (c) 2011 by The American Association for Thoracic Surgery doi:10.1016/j.jtcvs.2011.04.031
}

abetes, are closely linked to the calcific load and the degree of atherosclerosis. ${ }^{7}$

Off-pump coronary artery bypass surgery (OPCAB) is associated with a lower incidence of stroke, ${ }^{8,9}$ in addition to a comparable risk-adjusted mortality and less morbidity, especially in high-risk groups and elderly patients. ${ }^{8,10}$ However, inasmuch as stroke is multifactorial in origin, ${ }^{6}$ no single technique, including off-pump surgery, has accomplished the aim to eliminate postoperative stroke completely. ${ }^{9-11}$

The combination of off-pump techniques and total arterial grafting to offer a "no-touch approach" for coronary artery bypass grafting $(\mathrm{CABG})$ has been proposed to be the "gold standard" strategy to effectively reduce neurologic complications. ${ }^{12,13}$ Recent studies demonstrated that the aortic notouch technique is safe, effective ${ }^{14-16}$ and results in lower neurologic complications even in high-risk patients. ${ }^{17,18}$

Even though the no-touch technique may be the best clinical practice, it may not always be applicable for every patient and is not routinely applied in many centers. Whenever saphenous vein grafts or free arterial grafts are used, a proximal anastomosis is required that may either be performed by partial aortic clamping with side-biting clamps or in 


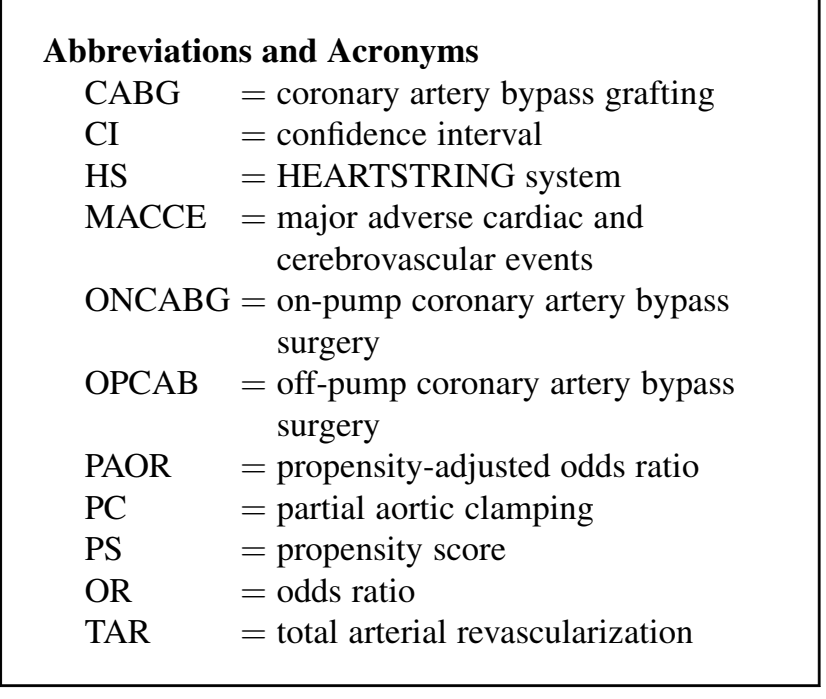

a no-touch fashion by composite arterial grafting and finally by using anastomotic devices such as the HEARTSTRING Proximal Seal System (Guidant Corporation, Indianapolis, Ind). ${ }^{4,19,20}$

In this study, we evaluate the safety of a standardized offpump operation with a specific focus on the impact of partial aortic clamping versus a no-touch technique using the HEARTSTRING Seal System on the incidence of postoperative stroke. Results were compared with those in patients undergoing off-pump all arterial grafting (no-touch).

\section{PATIENTS AND METHODS}

From 2004 to 2009, 4314 patients underwent myocardial revascularization at our institution. Patients underwent either OPCAB $(n=2203 ; 51 \%$; OPCAB, cohort A) or on-pump CABG $(n=2111 ; 49 \%$; ONCABG cohort $B)$. The OPCAB cohort was divided into 2 subgroups: (1) in patients requiring proximal anastomosis applying the partial aortic clamping technique ( $\mathrm{n}=567 ; 26 \%$; OPCAB-PC) or (2) using a no-touch clampless technique using the HEARTSTRING system (HS) $(\mathrm{n}=1365 ; 62 \%$; OPCAB-HS). Patients who had total arterial revascularization (TAR) without the need for proximal anastomosis $(\mathrm{n}=271 ; 12 \%$; OPCAB-TAR) (Figure 1$)$ served as a control group (gold standard) with regard to neurologic complications and major adverse cardiac and cerebrovascular events (MACCE).

Data collection was performed prospectively and was approved by our local institutional review board, including a waiver of informed consent. Preoperative risk stratification was performed using the EuroSCORE risk model. Demographics and preoperative variables are summarized in Tables 1 and 2 .

\section{SURGICAL TECHNIQUE}

OPCAB was performed as previously described. ${ }^{21}$ In brief, heparin was administered to obtain an activated clotting time in excess of 350 seconds and repeated if necessary. Epicardial temporary pacemaker wires were placed before a stabilizer (Octopus4 Tissue Stabilizer; Medtronic, Inc, Minneapolis, Minn) was used to expose the target vessel. A shunt (ClearView Intracoronary Shunt; Medtronic) was routinely inserted and a mister blower (Guidant) with carbon dioxide and water was used to clear the surgical field.
Routine ultrasound flow measurement (MediStim QuickFit probe; MediStim ASA, Oslo, Norway) was done in all cases.

If no total arterial grafting was performed, proximal anastomosis was carried out either with PC using a partial sidebiting clamp or in a clampless fashion (no-touch technique for proximal anastomosis) using the HEARTSTRING device. In brief, the surgeon used digital palpation to identify a healthy, noncalcified segment of aorta. Then an aortic punch device was used to create a circular aortotomy. The hole was occluded with the finger before insertion of the coiled HEARTSTRING device, which created a hemostatic seal against the inner wall of the aorta. The anastomosis was then performed with a continuous 6-0 Prolene suture (Ethicon, Inc, Somerville, NJ). After completion of the anastomosis and before tightening of the suture, the device was removed.

\section{STATISTICAL ANALYSIS}

\section{Comparison of OPCAB Versus ONCABG Cohort}

End points analyzed are mortality, stroke, and MACCE including death, myocardial infarction, recurrent angina, and stroke. A composite end point including major noncardiac adverse events such as respiratory failure, renal failure, and bleeding was created. For converted patients, the "intention-to-treat" methodology was applied.

\section{Comparison of OPCAB-PC Versus OPCAB-HS}

The major outcome variable of this analysis is the occurrence of postoperative stroke. It was defined in accordance with the definition of stroke published by the Northern New England Cardiovascular Disease Study Group. Stroke was defined as a new neurologic deficit that appears and remains at least partially evident for more than 24 hours after its onset and occurs during or after the CABG procedure; moreover, strokes needed to be diagnosed before discharge. Other than by clinical symptoms, diagnosis was confirmed by a neurologist and brain imaging. Transient ischemic attacks, intellectual impairment, confusion, or irritation were excluded. Patients who received no-touch TAR served as the control group (gold standard).

Continuous data are presented as mean \pm standard deviation and are compared using the Mann-Whitney test. Categorical data are presented as number and percentage and are compared using the $\chi^{2}$ test or Fisher's exact test where appropriate. Odds ratios (OR) with $95 \%$ confidence intervals (CI) are computed using univariate logistic regression. A propensity score (PS) was computed using logistic regression with 50 preoperative variables to balance characteristics between OPCAB and on-pump groups. In this computation, missing values in preoperative variables were replaced using regression methods. The PS then was divided into quintiles and analyzed as a categorical variable. PS-adjusted logistic regression analysis was performed to assess binary end points and 2-way analysis of variance 


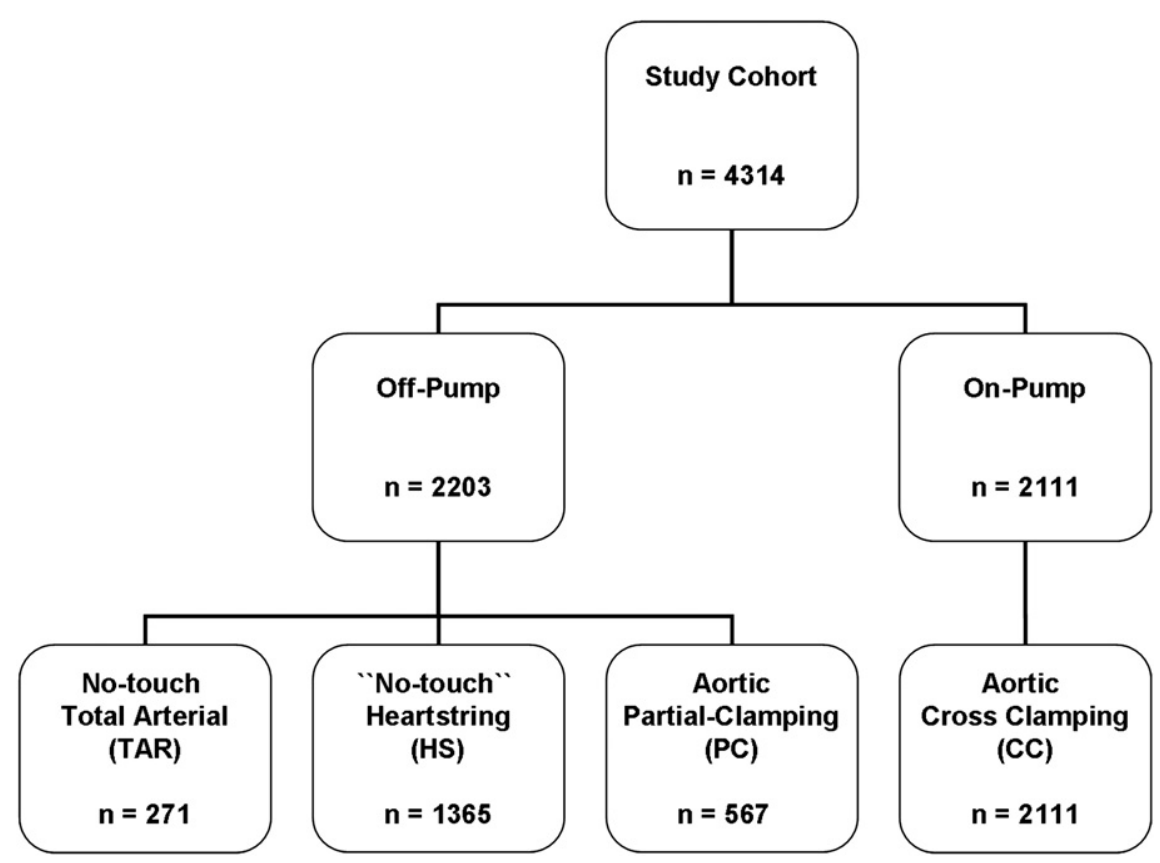

FIGURE 1. Study population and distribution of subgroups.

for continuous end points. The same methodology was used to create an additional PS to balance characteristics between the partial clamping subgroup and the no-touch HEARTSTRING system subgroup. All analyses were performed using SPSS 18 software (SPSS Inc, Chicago, Ill).

The data set of 50 preoperative variables for the PS included preoperative patient characteristics such as cardiovascular risk factors and comorbidities including cerebrovascular events, peripheral artery disease, chronic obstructive pulmonary disease, and renal failure. Cardiacrelated preoperative conditions were as follows: preceding myocardial infarction, myocardial infarction within 3 months before surgery, preceding cardiogenic shock, congestive heart failure, arrhythmias, number of diseased coronary vessels, previous CABG, elective, urgent/or emergency presentation, previous percutaneous transluminal coronary angioplasty, previous stent implantation, New York Heart Association class, Canadian Cardiovascular Society class, logistic EuroSCORE, and others. All analyses were performed using SPSS 18 software.

\section{RESULTS}

OPCAB Versus ONCABG Crude and PropensityAdjusted Outcome Data (Table 3, Figure 2)

The mortality rate was comparable for both cohorts $(1.6 \%$ vs $2.4 \% ; \quad$ OR $=0.66 ;$ CI $95 \%, 0.43-1.02$; $P=.067)$, whereas OPCAB patients had significantly fewer MACCE (7.9\% vs $17.1 \%$; OR $=0.41$; CI 95\%, 0.34-0.50; $P<.0001)$. In detail, OPCAB patients had a significant benefit in regard to stroke $(1.1 \%$ vs $2.4 \%$; OR $=0.45 ;$ CI $95 \%$, $0.27-0.74 ; P=.002)$, myocardial infarction $(1.1 \%$ vs $2.2 \% ;$ OR $=0.51 ;$ CI $95 \%, 0.28-0.93 ; P=.028)$, low

TABLE 1. Preoperative characteristics and demographics

\begin{tabular}{|c|c|c|c|c|c|c|}
\hline Parameter & OPCAB $(n=2203)$ & ONCABG $(n=2111)$ & $P$ value & OPCAB-PC $(n=567)$ & OPCAB-HS $(n=1365)$ & $P$ value \\
\hline Age (y) & $65 \pm 10$ & $63 \pm 9$ & .002 & $63 \pm 10$ & $66 \pm 10$ & .001 \\
\hline Male $(\%)$ & 79.2 & 82.6 & .004 & 79.0 & 79.4 & .85 \\
\hline EuroSCORE & $3.87 \pm 1.09$ & $4.07 \pm 1.19$ & .001 & $3.75 \pm 1.03$ & $3.66 \pm 1.12$ & .031 \\
\hline $\mathrm{EF}(\%)$ & $57 \pm 14$ & $56 \pm 14$ & .008 & $57 \pm 15$ & $57 \pm 14$ & .74 \\
\hline Elective $(\%)$ & 70.5 & 64.5 & .001 & 74.3 & 68.0 & .006 \\
\hline Urgent $(\%)$ & 23,5 & 31.7 & .001 & 18,7 & 25.3 & .001 \\
\hline Emergency $(\%)$ & 6.0 & 3.8 & .01 & 7.1 & 6.2 & .54 \\
\hline Sinus rhythm $(\%)$ & 96.7 & 97.1 & .53 & 94.8 & 97.3 & .07 \\
\hline Atrial fibrillation (\%) & 2.1 & 2.0 & 1.00 & 1.9 & 2.1 & 1.00 \\
\hline No. of diseased vessels & $2.68 \pm 0.56$ & $2.95 \pm 0.24$ & .001 & $2.71 \pm 0.54$ & $2.62 \pm 0.61$ & .009 \\
\hline Left main disease $(\%)$ & 29.5 & 24.8 & .001 & 25.2 & 30.3 & .027 \\
\hline Redo surgery $(\%)$ & 3.7 & 8.1 & .001 & 4.9 & 3.1 & .06 \\
\hline
\end{tabular}

$O P C A B$, Off-pump coronary artery bypass surgery; $O N C A B G$, on-pump coronary artery bypass surgery; $P C$, partial clamping; $H S$, HEARTSTRING system; $E F$, ejection fraction. 
TABLE 2. Risk factors and comorbidities

\begin{tabular}{|c|c|c|c|c|c|c|}
\hline Parameter & $\begin{array}{c}\text { OPCAB } \\
(\mathbf{n}=\mathbf{2 2 0 3})\end{array}$ & $\begin{array}{l}\text { ONCABG } \\
(n=2111) \\
\end{array}$ & $P$ value & $\begin{array}{c}\text { OPCAB-PC } \\
(\mathrm{n}=567)\end{array}$ & $\begin{array}{c}\text { OPCAB-HS } \\
\mathbf{n}=\mathbf{1 3 6 5} \\
\end{array}$ & $P$ value \\
\hline Hypercholesterinemia (\%) & 72.2 & 76.7 & .004 & 75.4 & 72.2 & .33 \\
\hline Hypertension $(\%)$ & 51.0 & 62.8 & $<.0001$ & 38.4 & 54.7 & $<.0001$ \\
\hline Positive family history $(\%)$ & 34.8 & 35.0 & .92 & 37.6 & 34.1 & .16 \\
\hline Diabetes $(\%)$ & 24.5 & 22.5 & .12 & 23.6 & 25.1 & .52 \\
\hline Smoking (\%) & 54.2 & 56.5 & .15 & 55.6 & 54.4 & .69 \\
\hline Adipositas (\%) & 53.6 & 40.5 & $<.0001$ & 53.6 & 53.8 & .96 \\
\hline $\operatorname{PAD}(\%)$ & 15.0 & 13.5 & .16 & 14.7 & 15.4 & .72 \\
\hline COPD $(\%)$ & 5.7 & 7.9 & .004 & 4.8 & 6.0 & .33 \\
\hline Acute MI $(<90 \mathrm{~d})(\%)$ & 17.3 & 22.1 & .01 & 16.4 & 17.4 & .60 \\
\hline Previous MI (>90 d) $(\%)$ & 37.8 & 44.5 & .001 & 39.3 & 37.4 & .44 \\
\hline Preoperative CS (\%) & 1.1 & 1.4 & .57 & 1.5 & 0.9 & .49 \\
\hline Cerebrovascular disease $(\%)$ & 1.6 & 1.1 & .14 & 0.9 & 1.7 & .21 \\
\hline Renal disease $(\%)$ & 4.0 & 2.1 & .001 & 4.5 & 3.8 & .59 \\
\hline
\end{tabular}

$O P C A B$, Off-pump coronary artery bypass surgery; $O N C A B G$, on-pump coronary artery bypass surgery; $P C$, partial clamping; $H S$, HEARTSTRING system; $P A D$, peripheral artery disease; $C O P D$, chronic obstructive pulmonary disease; $M I$, myocardial infarction; $C S$, cardiogenic shock.

cardiac output $(1.9 \%$ vs $3.3 \%$; OR $=0.55$; CI $95 \%, 0.31$ $0.95 ; P=.035)$, and arrhythmia $(1.6 \%$ vs $3.1 \%$; $\mathrm{OR}=0.52$; CI $95 \%, 0.29-0.93 ; P=.029)$. The occurrence of the noncardiac composite was significantly lower among patients who received off-pump surgery $(9.8 \%$ vs $17.9 \%$; $\mathrm{OR}=0.49 ;$ CI $95 \%, 0.41-0.60 ; P<.0001)$.

After PS adjustment, the mortality rate appeared to be even significantly lower among OPCAB patients (propensity-adjusted OR $[\mathrm{PAOR}]=0.51 ; \mathrm{CI} 95 \%, 0.26-0.99$; $P=.047$ ). The occurrence of MACCE (PAOR $=0.67$; CI $95 \%, 0.52-0.84 ; P=.001)$ including myocardial infarction $(\mathrm{PAOR}=0.50 ; \mathrm{CI} 95 \%, 0.26-0.98 ; P=.044)$ and stroke $(\mathrm{PAOR}=0.35 ; \mathrm{CI} 95 \%, 0.17-0.72 ; P=.005)$ remained sig- nificantly lower after adjustment. Likewise, the noncardiac composite was still significantly lower after OPCAB $(\mathrm{PAOR}=0.65 ; \mathrm{CI} 95 \%, 0.51-0.82 ; P<.0001)$.

\section{PC Versus No-Touch HS (Table 4, Figure 2)}

OPCAB patients undergoing the no-touch HS approach had significantly fewer MACCE $(6.7 \%$ vs $10.8 \%$; $\mathrm{OR}=0.59$; CI $95 \%, 0.42-0.83 ; P=.003)$ owing to a significantly lower rate of stroke $(0.7 \%$ vs $2.3 \%$; OR $=0.28$; CI $95 \%, 0.12-0.66 ; P=.004)$. Myocardial infarction also appeared to be less prevalent among these patients $(0.9 \%$ vs $1.9 \%$; OR $=0.48$; CI 95\%, 0.15-1.53; $P=.22$ ), although failing to achieve statistical significance. After PS

TABLE 3. Crude outcome and propensity-adjusted outcome

\begin{tabular}{|c|c|c|c|c|c|c|c|c|}
\hline Parameter & $\begin{array}{c}\text { OPCAB } \\
(\mathbf{n}=\mathbf{2 2 0 3})\end{array}$ & $\begin{array}{l}\text { ONCABG } \\
(\mathbf{n}=\mathbf{2 1 1 1})\end{array}$ & OR & CI 95\% & $P$ value & PAOR & PA CI 95\% & PA $P$ value \\
\hline Mortality (\%) & 1.6 & 2.4 & 0.66 & $0.43-1.02$ & .067 & 0.51 & $0.26-0.99$ & .047 \\
\hline Neurologic events (central) $(\%)$ & 1.1 & 2.4 & 0.45 & $0.27-0.74$ & .002 & 0.35 & $0.17-0.72$ & .005 \\
\hline Neurologic events (peripheral) $(\%)$ & 0.5 & 0.6 & 0.73 & $0.32-1.68$ & .47 & 0.41 & $0.1-1.71$ & .22 \\
\hline Rethoracotomy for bleeding (\%) & 4.3 & 6.1 & 0.68 & $0.52-0.89$ & .006 & 0.75 & $0.52-1.08$ & .12 \\
\hline Myocardial infarction $(\%)$ & 1.1 & 2.2 & 0.51 & $0.28-0.93$ & .028 & 0.50 & $0.26-0.98$ & .044 \\
\hline Low cardiac output $(\%)$ & 1.9 & 3.3 & 0.55 & $0.31-0.95$ & .035 & 0.68 & $0.37-1.28$ & .24 \\
\hline Graft occlusion $(\%)$ & 1.4 & 1.7 & 0.83 & $0.43-1.62$ & .60 & 0.70 & $0.32-1.51$ & .36 \\
\hline Arrhythmia $(\%)$ & 1.6 & 3.1 & 0.52 & $0.29-0.93$ & .029 & 0.76 & $0.38-1.51$ & .43 \\
\hline IABP postop $(\%)$ & 0.2 & 1.5 & 0.14 & $0.05-0.38$ & $<.0001$ & 0.22 & $0.07-0.64$ & .005 \\
\hline Renal dysfunction (\%) & 3.9 & 6.0 & 0.63 & $0.47-0.84$ & .001 & 0.70 & $0.48-1.03$ & .07 \\
\hline Ventilation $<12 \mathrm{~h}(\%)$ & 57.8 & 35.5 & 2.48 & $2.18-2.83$ & $<.0001$ & 1.53 & $1.27-1.84$ & $<.0001$ \\
\hline Prolonged ventilation $>24 \mathrm{~h}(\%)$ & 7.5 & 12.0 & 0.59 & $0.44-0.74$ & $<.0001$ & 0.76 & $0.56-1.04$ & .088 \\
\hline Respiratory failure (\%) & 1.6 & 3.9 & 0.41 & $0.23-0.73$ & .003 & 0.42 & $0.22-0.80$ & .008 \\
\hline Pleural effusions/pneumothorax (\%) & 3.5 & 6.3 & 0.54 & $0.38-0.78$ & .001 & 0.58 & $0.39-0.86$ & .007 \\
\hline Sinus rhythm $(\%)$ & 93.2 & 95.1 & 0.70 & $0.52-0.94$ & .02 & 0.62 & $0.44-0.89$ & .01 \\
\hline Atrial fibrillation $(\%)$ & 5.6 & 3.9 & 1.46 & $1.02-203$ & .024 & 1.84 & $1.26-2.69$ & .002 \\
\hline $\operatorname{MACCE}(\%)$ & 7.9 & 17.1 & 0.41 & $0.34-0.50$ & $<.0001$ & 0.67 & $0.52-0.84$ & .001 \\
\hline Noncardiac composite $(\%)$ & 9.8 & 17.9 & 0.50 & $0.41-0.60$ & $<.0001$ & 0.65 & $0.51-0.82$ & $<.0001$ \\
\hline
\end{tabular}

$O P C A B$, Off-pump coronary artery bypass surgery; $C A B G$, coronary artery bypass grafting; $O R$, odds ratio; $C I 95 \%$, confidence interval $95 \%$; $P A O R$, propensity-adjusted odds ratio; $P A C I 95 \%$, propensity-adjusted confidence interval $95 \% ; P A$ P value, propensity-adjusted $P$ value; IABP, intra-aortic balloon pump; MACCE, major adverse cardiac and cerebrovascular events. 


\section{Mortality}

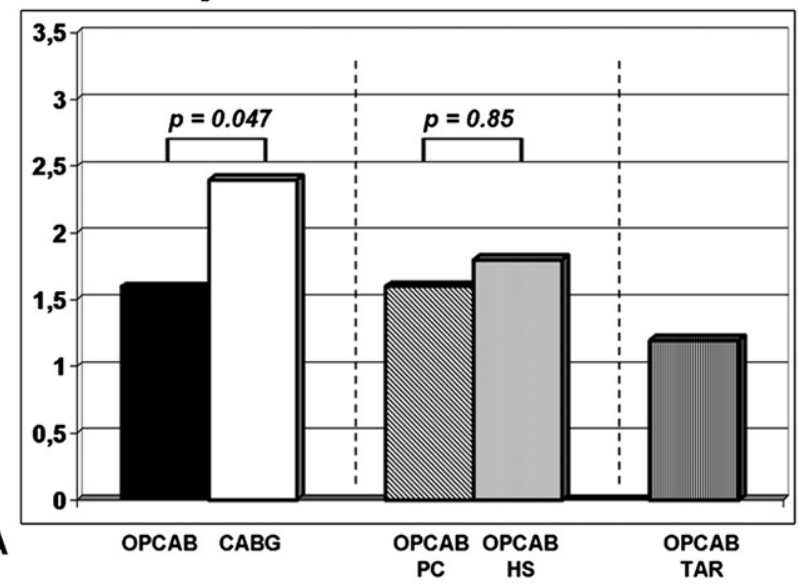

Myocardial Infarction

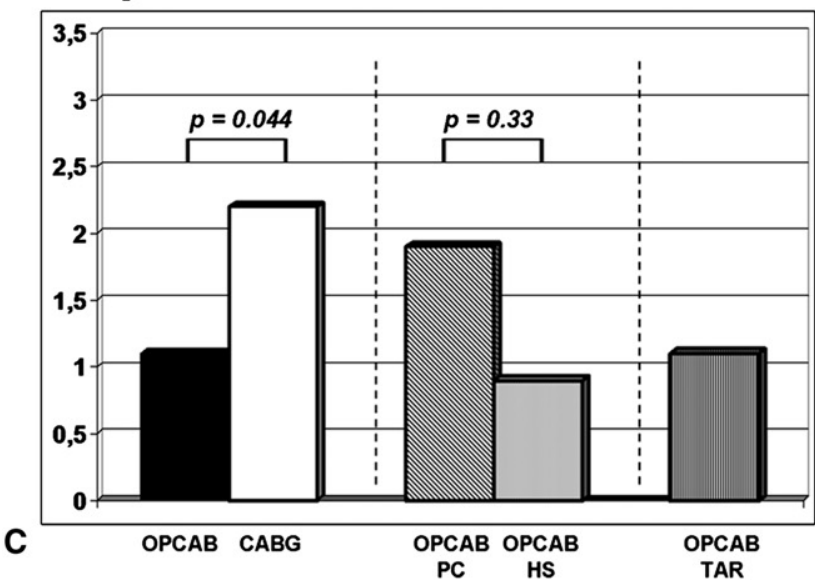

\section{Stroke}

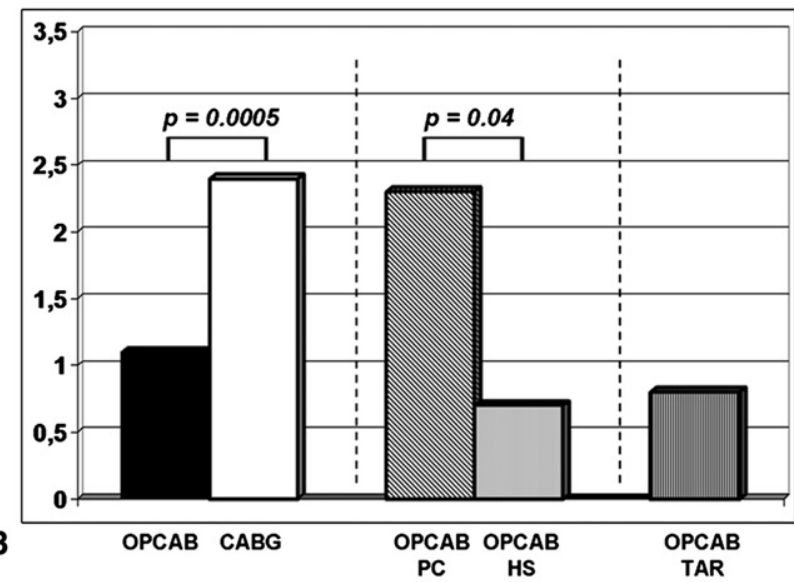

MACCE

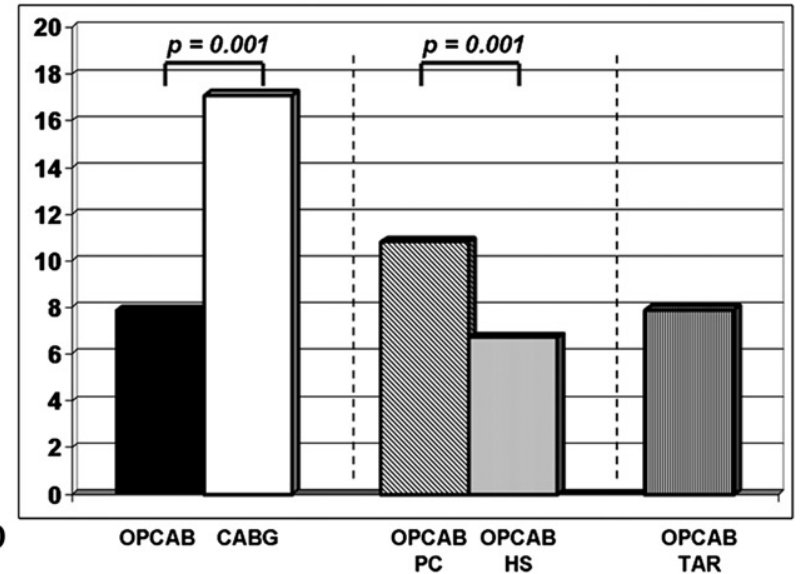

FIGURE 2. Outcome data, OPCAB versus on-pump CABG, and OPCAB-PC versus OPCAB-HS. After propensity score adjustment, OPCAB appeared to be significantly beneficial with regard to mortality (A), stroke (B), myocardial infarction (C), and MACCE (D) when compared with on-pump surgery (left columns). In comparison with partial clamping, OPCAB patients who underwent the HEARTSTRING system approach presented with significantly lower frequencies of stroke and MACCE (middle columns) yielding similar to the control group who underwent no-touch TAR (right column). OPCAB, Off-pump coronary artery bypass surgery; $C A B G$, coronary artery bypass grafting; $P C$, partial clamping; $H S$, HEARTSTRING system; $M A C C E$, major adverse cardiac and cerebrovascular events; TAR, total arterial revascularization.

adjustment, the stroke rate $(\mathrm{PAOR}=0.39$; CI 95\%, 0.16$0.90 ; P=.04)$ and the overall occurrence of MACCE $(\mathrm{PAOR}=0.55 ; \mathrm{CI} 95 \%, 0.38-0.79 ; P=.001)$ remained significantly less in patients who received proximal anastomosis applying the HEARTSTRING device.
In comparison, the control patients who underwent TAR without the need for proximal anastomosis ( $\mathrm{n}=271 ; 12 \%$; OPCAB-TAR) (Figure 1 ) had a stroke rate of $0.8 \%$, myocardial infarction rate of $1.1 \%$, and an overall MACCE of $7.9 \%$. Mortality was $1.2 \%$ and

TABLE 4. Partial clamping versus HEARTSTRING system

\begin{tabular}{|c|c|c|c|c|c|c|c|c|}
\hline Parameter & $\begin{array}{c}\text { OPCAB-PC } \\
(n=567)\end{array}$ & $\begin{array}{c}\text { OPCAB-HS } \\
(n=1365)\end{array}$ & OR & CI 95\% & $P$ value & PAOR & PACI 95\% & $\begin{array}{c}\text { PA } \\
P \text { value } \\
\end{array}$ \\
\hline Mortality (\%) & 1.6 & 1.8 & 0.91 & $0.42-1.93$ & .81 & 1.07 & $0.49-2.36$ & .85 \\
\hline Neurologic events (central) $(\%)$ & 2.3 & 0.7 & 0.28 & $0.12-0.66$ & .004 & 0.39 & $0.16-0.90$ & .04 \\
\hline Myocardial infarction (\%) & 1.9 & 0.9 & 0.48 & $0.15-1.53$ & .22 & 0.55 & $0.16-1.85$ & .33 \\
\hline MACCE $(\%)$ & 10.8 & 6.7 & 0.59 & $0.42-0.83$ & .003 & 0.55 & $0.38-0.79$ & .001 \\
\hline
\end{tabular}

$P C$, Partial clamping; $H S$, HEARTSTRING system; $O P C A B$, off-pump coronary artery bypass surgery; $O R$, odds ratio; $C I 95 \%$, confidence interval $95 \%$; $P A O R$, propensityadjusted odds ratio; $P A C I$ 95\%, propensity-adjusted confidence interval $95 \%$; $P A \mathrm{P}$ value, propensity-adjusted $P$ value; $M A C C E$, major adverse cardiac and cerebrovascular events. 
TABLE 5. Intraoperative data and used grafts

\begin{tabular}{|c|c|c|c|c|c|c|c|}
\hline Parameter & $\begin{array}{c}\text { OPCAB } \\
(\mathbf{n}=\mathbf{2 2 0 3})\end{array}$ & $\begin{array}{c}\text { ONCAB } \\
(n=2111)\end{array}$ & $P$ value & $\begin{array}{c}\text { OPCAB-PC } \\
(\mathbf{n}=\mathbf{5 6 7})\end{array}$ & $\begin{array}{c}\text { OPCAB-HS } \\
(\mathbf{n}=\mathbf{1 3 6 5})\end{array}$ & $P$ value & $\begin{array}{l}\text { OPCAB-TAR control } \\
(\mathbf{n}=\mathbf{2 7 1})\end{array}$ \\
\hline Diseased vessels & $2.68 \pm 0.55$ & $2.95 \pm 0.24$ & .001 & $2.62 \pm 0.61$ & $2.71 \pm 0.53$ & .009 & $1.93 \pm 0.74$ \\
\hline Total grafts & $3.29 \pm 1.09$ & $3.85 \pm 0.82$ & .001 & $3.24 \pm 1.20$ & $3.33 \pm 1.05$ & .25 & $1.76 \pm 0.87$ \\
\hline Arterial grafts & $1.63 \pm 0.91$ & $1.31 \pm 0.79$ & $<.0001$ & $1.60 \pm 0.91$ & $1.49 \pm 0.80$ & .01 & $1.76 \pm 0.87$ \\
\hline SVG & $1.66 \pm 1.25$ & $2.54 \pm 1.12$ & $<.0001$ & $1.64 \pm 1.26$ & $1.85 \pm 1.20$ & .001 & $\mathrm{n} / \mathrm{a}$ \\
\hline LITA $(\%)$ & 95.1 & 93.8 & .06 & 97.0 & 95.2 & .08 & 92.3 \\
\hline RITA (\%) & 40.9 & 22.0 & $<.0001$ & 42.2 & 37.0 & .04 & 36.1 \\
\hline Radial artery (\%) & 12.9 & 5.6 & $<.0001$ & 9.9 & 10.2 & .80 & 13.6 \\
\hline SVG $(\%)$ & 76.1 & 91.2 & $<.0001$ & 75.0 & 83.2 & .001 & $\mathrm{n} / \mathrm{a}$ \\
\hline
\end{tabular}

$O P C A B$, Off-pump coronary artery bypass surgery; $O N C A B$, on-pump coronary artery bypass surgery; $P C$, partial clamping; $H S$, HEARTSTRING system; TAR, total arterial revascularization; LITA, left internal thoracic artery; RITA, right internal thoracic artery; SVG, saphenous vein graft.

the noncardiac composite occurred in $10.8 \%$ of all patients (Figure 2).

\section{Intraoperative Data and Used Grafts}

The mean numbers of diseased vessels and applied grafts are summarized in Table 5. In brief, ONCABG patients presented with a higher number of diseased vessels $(2.68 \pm$ 0.55 vs $2.95 \pm 0.24 ; P=.001)$ and also received an overall higher number of grafts $(3.29 \pm 1.09$ vs $3.85 \pm 0.82$; $P=.001)$. In contrast, OPCAB patients received more arterial grafts $(1.63 \pm 0.91$ vs $1.31 \pm 0.79 ; P<.0001)$. When comparing OPCAB-PC versus OPCAB-HS, there was no difference with regard to the total number of grafts (3.24 \pm 1.20 vs $3.33 \pm 1.05 ; P=.25$ ), whereas the number of diseased vessels was slightly higher in the OPCAB HS group $(2.62 \pm 0.61$ vs $2.71 \pm 0.53 ; P=.009)$ (Table 5).

\section{DISCUSSION}

The data presented herein once again confirm the superiority of an aortic no-touch strategy in patients undergoing surgical revascularization. The occurrence of stroke and MACCE can be significantly reduced by using the HEARTSTRING device, yielding results similar to those that can be achieved with the gold standard-no-touch TAR OPCAB.

There was no difference in the rate of stroke between patients who underwent a conventional on-pump approach with aortic crossclamping and patients who received offpump surgery in combination with PC for proximal anastomosis. This suggests that not the type of clamping, but clamping itself is an independent predictor for an increased risk of stroke. ${ }^{22}$ Various studies have proven embolic showers using transcranial Doppler during cannulation, clamping, or declamping maneuvers and especially in association with the release of the aortic crossclamp. ${ }^{23,24}$ Our data are supported by Lev-Ran and colleagues, ${ }^{22}$ who compared 429 patients who underwent aortic no-touch technique versus 271 patients in whom a partial aortic clamp was applied. The authors detected a significantly lower incidence of stroke in the no-touch group and identified PC as a independent predictor of stroke. ${ }^{22}$ In comparison with our study, the authors compared no-touch TAR versus PC, whereas our study aimed at the comparison between the no-touch HS technique versus PC. Therefore, aortic manipulation must be avoided whenever possible. ${ }^{12}$

$\mathrm{OPCAB}$ has been reported to reduce the risk for neurologic complications by eliminating the need for cardiopulmonary bypass requiring aortic cannulation and aortic crossclamping $^{3,6,15}$; and, indeed, off-pump surgery combined with all arterial grafting has been suggested to be currently the ideal approach to reduce stroke after bypass surgery. ${ }^{12,13,22}$ However, and despite all evidence in favor of no-touch TAR, the real world does still include saphenous vein grafting with proximal anastomosis in patients with multivessel disease. This further highlights the importance of our findings, inasmuch as a significant stroke reduction can be achieved by avoiding aortic clamping. This deviceenabled approach is easily implemented by the described technique. In line with our study, Douglas and Spaniol ${ }^{4}$ reported a stroke rate of $0.8 \% \mathrm{OPCAB}$ in combination with the HEARTSTRING device. The authors stressed the role of clampless OPCAB as an important tool for the prevention of postoperative stroke and also concluded that adjunctive techniques for the prevention of emboli from the ascending aorta may further reduce the risk of stroke. ${ }^{4}$

In another report, Halbersma and coworkers ${ }^{13}$ recently suggested OPCAB no-touch with total arterial Y-graft as the best treatment option. They presented 4-year data of 400 consecutive patients that were compared with the surgical arm of the SYNTAX trial with regard to neurologic outcome. The authors identified a clear trend toward a reduction of stroke $(0.8 \%)$ compared with the surgical arm of the SYNTAX trial $(2.2 \%) .{ }^{13}$ However, this is not always possible as desired by the surgeon. For these patients, the HEARTSTRING device is a safe and efficient alternative. ${ }^{4,19,20}$ The occurrence of stroke or other neurologic complications can be significantly minimized with such an anastomotic device when compared with the standard techniques, particularly in patients with a high atherosclerotic burdon. ${ }^{25,26}$

This is an important message, particularly when the outcomes of percutaneous coronary intervention and CABG 
are compared. Recent studies ${ }^{5,27,28}$ including the SYNTAX reference trial ${ }^{5}$ and the ARTS-II trial ${ }^{27}$ reported a higher incidence of stroke in the CABG group and created a major concern for surgical revascularization. The low stroke rate associated with a standardized OPCAB no-touch strategy, either using all arterial grafting or the HEARTSTRING device when a proximal anastomosis is required, can address this concern. This finding is supported by a recent trial of Briguori and colleagues, ${ }^{29}$ who did not detect a higher incidence for stroke when comparing outcomes after drugeluting stent implantation versus OPCAB in patients with multivessel disease. ${ }^{29}$

The risk of stroke cannot be completely eliminated after surgical revascularization. However, this also applies to interventional approaches ${ }^{5,27-29}$ and is most probably linked to the multifactorial origin of stroke and the underlying risk profile defined by the individual health condition of a patient. ${ }^{6}$

Owing to its retrospective nature and nonrandomized design, all established disadvantages apply. Selection bias may be present as distribution to CABG versus OPCAB was done on surgeon's preference. Inasmuch as this is a teaching hospital, surgeons have always been free to apply whatever technique they preferred, whether OPCAB or CABG. PSs are valuable and helpful tools, but the allocation of a patient to either off- or on-pump surgery is based on criteria that may be buried at the time of the decision. Although balancing scores constitute the most rigorous methods available for apples-to-apples investigation of causal effects on outcome in the retrospective, nonrandomized setting, they are not equal to randomized clinical trials. ${ }^{30}$ Indeed, intraoperative digital palpation is less accurate than epiaortic ultrasound, which can be considered the "gold standard" for detection and characterization of atherosclerotic plaques in the ascending aorta. In numerous studies, epiaortic ultrasound has proved to be more precise than palpation for detecting aortic plaque. ${ }^{31}$ However, as in many surgical centers, this was not implemented in our daily practice.

In summary, our results confirm off-pump surgery to be very beneficial with regard to risk-adjusted outcomes and our data highlight that there is no difference in the occurrence of stroke when comparing aortic crossclamping in the setting of CABG to OPCAB with partial clamping. Whenever a proximal anastomosis is needed, the HEARTSTRING device is an excellent alternative to effectively reduce neurologic complications down to the level of the gold standard, that is, no-touch TAR using OPCAB.

\section{References}

1. Puskas JD, Winston AD, Wright CE, Gott JP, Brown WM 3rd, Craver JM, et al. Stroke after coronary artery operation: incidence, correlates, outcome, and cost. Ann Thorac Surg. 2000;69:1053-6.

2. Roach GW, Kanchuger M, Mangano CM, Newman M, Nussmeier N, Wolman R, et al. Adverse cerebral outcomes after coronary bypass surgery. Multicenter
Study of Perioperative Ischemia Research Group and the Ischemia Research and Education Foundation Investigators. N Engl J Med. 1996;335:1857-63.

3. Brizzio ME, Zapolanski A, Shaw RE, Sperling JS, Mindich BP. Stroke-related mortality in coronary surgery is reduced by the off-pump approach. Ann Thorac Surg. 2010;89:19-23

4. Douglas JM Jr, Spaniol SE. A multimodal approach to the prevention of postoperative stroke in patients undergoing coronary artery bypass surgery. Am J Surg. 2009; 197:587-90.

5. Serruys PW, Morice MC, Kappetein AP, Colombo A, Holmes DR, Mack MJ, et al. Percutaneous coronary intervention versus coronary-artery bypass grafting for severe coronary artery disease. N Engl J Med. 2009;360:961-72.

6. Bucerius J, Gummert JF, Borger MA, Walther T, Doll N, Onnasch JF, et al. Stroke after cardiac surgery: a risk factor analysis of 16,184 consecutive adult patients. Ann Thorac Surg. 2003;75:472-8.

7. Hilker M, Arlt M, Keyser A, Schopka S, Klose A, Diez C, et al. Minimizing the risk of perioperative stroke by clampless off-pump bypass surgery: a retrospective observational analysis. J Cardiothorac Surg. 2010;5:14.

8. Puskas JD, Williams WH, Duke PG, Staples JR, Glas KE, Marshall JJ, et al. Offpump coronary artery bypass grafting provides complete revascularization with reduced myocardial injury, transfusion requirements, and length of stay: a prospective randomized comparison of two hundred unselected patients undergoing off-pump versus conventional coronary artery bypass grafting. J Thorac Cardiovasc Surg. 2003;125:797-808.

9. Sedrakyan A, Wu AW, Parashar A, Bass EB, Treasure T. Off-pump surgery is as sociated with reduced occurrence of stroke and other morbidity as compared with traditional coronary artery bypass grafting: a meta-analysis of systematically reviewed trials. Stroke. 2006;37:2759-69.

10. Puskas JD, Thourani VH, Kilgo P, Cooper W, Vassiliades T, Vega JD, et al. Offpump coronary artery bypass disproportionately benefits high-risk patients. Ann Thorac Surg. 2009;88:1142-7.

11. van Dijk D, Keizer AM, Diephuis JC, Durand C, Vos LJ, Hijman R. Neurocognitive dysfunction after coronary artery bypass surgery: a systematic review. $J$ Thorac Cardiovasc Surg. 2000;120:632-9.

12. Falk V. Stay off-pump and do not touch the aorta! Eur Heart J. 2010;31:278-80.

13. Halbersma WB, Arrigoni SC, Mecozzi G, Grandjean JG, Kappetein AP, van der Palen J, et al. Four-year outcome of OPCAB no-touch with total arterial Y-graft: making the best treatment a daily practice. Ann Thorac Surg. 2009;88: 796-801.

14. Kim WS, Lee J, Lee YT, Sung K, Yang JH, Jun TG, et al. Total arterial revascularization in triple-vessel disease with off-pump and aortic no-touch technique. Ann Thorac Surg. 2008;86:1861-5.

15. Navia D, Vrancic M, Vaccarino G, Piccinini F, Raich H, Florit S, et al. Total arterial off-pump coronary revascularization using bilateral internal thoracic arteries in triple-vessel disease: surgical technique and clinical outcomes. Ann Thorac Surg. 2008;86:524-30.

16. Tagusari O, Kobayashi J, Bando K, Niwaya K, Nakajima H, Nakatani T, et al. Total arterial off-pump coronary artery bypass grafting for revascularization of the total coronary system: clinical outcome and angiographic evaluation. Ann Thorac Surg. 2004;78:1304-11; discussion 1304-11.

17. Hernandez F Jr, Brown JR, Likosky DS, Clough RA, Hess AL, Roth RM, et al Neurocognitive outcomes of off-pump versus on-pump coronary artery bypass: a prospective randomized controlled trial. Ann Thorac Surg. 2007;84:1897-903.

18. Selnes OA, Grega MA, Bailey MM, Pham L, Zeger S, Baumgartner WA, et al. Neurocognitive outcomes 3 years after coronary artery bypass graft surgery: a controlled study. Ann Thorac Surg. 2007;84:1885-96.

19. Lamm P, Eifert S, Kilian E, Reichart B, Juchem G. Preventing blood loss during application of the HEARTSTRING proximal seal system. Ann Thorac Surg. 2009;88:310-2.

20. Shimokawa T, Manabe S, Sawada T, Matsuyama S, Fukui T, Takanashi S. Intermediate-term patency of saphenous vein graft with a clampless hand-sewn proximal anastomosis device after off-pump coronary bypass grafting. Ann Thorac Surg. 2009;87:1416-20.

21. Emmert MY, Salzberg SP, Seifert B, Schurr UP, Hoerstrup SP, Reuthebuch O, et al. Routine off-pump coronary artery bypass grafting is safe and feasible in high-risk patients with left main disease. Ann Thorac Surg. 2010;89:1125-30.

22. Lev-Ran O, Braunstein R, Sharony R, Kramer A, Paz Y, Mohr R, et al. No-touch aorta off-pump coronary surgery: the effect on stroke. J Thorac Cardiovasc Surg. 2005; 129:307-13.

23. Diegeler A, Hirsch R, Schneider F, Schilling LO, Falk V, Rauch T, et al. Neuromonitoring and neurocognitive outcome in off-pump versus conventional coronary bypass operation. Ann Thorac Surg. 2000;69:1162-6. 
24. Guerrieri Wolf L, Abu-Omar Y, Choudhary BP, Pigott D, Taggart DP. Gaseous and solid cerebral microembolization during proximal aortic anastomoses in off-pump coronary surgery: the effect of an aortic side-biting clamp and two clampless devices. J Thorac Cardiovasc Surg. 2007;133: 485-93.

25. Patel NC, Deodhar AP, Grayson AD, Pullan DM, Keenan DJ, Hasan R, et al. Neurological outcomes in coronary surgery: independent effect of avoiding cardiopulmonary bypass. Ann Thorac Surg. 2002;74:400-5; discussion 405-6.

26. Sisillo E, Marino MR, Juliano G, Beverini C, Salvi L, Alamanni F. Comparison of on pump and off pump coronary surgery: risk factors for neurological outcome. Eur J Cardiothorac Surg. 2007;31:1076-80.

27. Daemen J, Kuck KH, Macaya C, LeGrand V, Vrolix M, Carrie D, et al. Multivessel coronary revascularization in patients with and without diabetes mellitus: 3-year follow-up of the ARTS-II (Arterial Revascularization Therapies StudyPart II) trial. J Am Coll Cardiol. 2008;52:1957-67.

28. Moreno R, Fernández C, Hernández R, Alfonso F, Angiolillo DJ, Sabaté M, et al. Drug-eluting stent thrombosis: results from a pooled analysis including 10 randomized studies. J Am Coll Cardiol. 2005;45:954-9.

29. Briguori C, Condorelli G, Airoldi F, Focaccio A, D'Andrea D, Cannavale M, et al. Comparison of coronary drug-eluting stents versus coronary artery bypass grafting in patients with diabetes mellitus. Am J Cardiol. 2007;99:779-84.

30. Blackstone EH. Comparing apples and oranges. J Thorac Cardiovasc Surg. 2002; 123:8-15.

31. Suvarna S, Smith A, Stygall J, Kolvecar S, Walesby R, Harrison M, et al. An intraoperative assessment of the ascending aorta: a comparison of digital palpation, transesophageal echocardiography, and epiaortic ultrasonography. J Cardiothorac Vasc Anesth. 2007;1:805-9. 